\title{
La comicidad en el teatro infantil de Concha Méndez
}

Raquel Molina-Angulo

Universitat de Lleida

La risa y el misterio juntos era siempre ellal.

Concepción Méndez Cuesta, conocida con el nombre artístico de Concha Méndez, nació el 27 de julio de 1898 en Madrid y falleció el 7 de diciembre de 1986 en México, país en el que se exilió a causa de sus convicciones republicanas ${ }^{2}$. Esta condición no fue la única dificultad que debió enfrentar: su condición de mujer fue la principal causa para ser discriminada tanto a nivel social como en el seno doméstico. La familia de Concha nunca aceptó que estudiara, según manifiesta la propia autora a propósito de la reacción que tuvo su madre cuando se enteró que había asistido a la universidad. Así lo explica su nieta, Paloma Ulacia Altolaguirre, en la biografía que publicó sobre su abuela intitulada Concha Méndez. Memorias habladas, memorias armadas:

Me hubiera gustado ir a la universidad. Un día acudí de oyente a un curso de literatura geográfica [...]. Volví muy contenta a casa. Entré. Mi madre hablaba por teléfono y me llamó: "Venga usted aquí". Al acercarme, me dio con la bocina en la cabeza. Me dio porque se había enterado por un hermano de mi presencia en la universidad. Me abrió la sien y me salió un chorro de sangre; del golpe sentí que se me había ido Dios

1. Palabras de María Zambrano, sobre Concha Méndez, recogidas en Paloma Ulacia Altolaguirre, Memorias habladas, memorias armadas, Renacimiento, Sevilla, 2018, p. 7.

2. Este camino del exilio en 1939 fue emprendido por otras autoras coetáneas suyas como Elena Fortún, María Zambrano o Magda Donato. 
a quién sabe dónde. Tuvieron que vendarme la cabeza y aún guardo la cicatriz. Ya era mayor de edad y pisar la universidad era imposible ${ }^{3}$.

Pese a las reticencias y obstáculos que interponía su familia a su formación, los anhelos de Concha Méndez por seguir aprendiendo y forjarse como poeta y dramaturga no cesaron. Su obra emergió con fuerza en una etapa cultural e histórica en la que las vanguardias se desarrollaron en España. Pero la discriminación volvió a hacerse presente, pues su obra no fue valorada en aquel tiempo como merecía; puede afirmarse que solo a partir de la última década del siglo XX ha empezado a ser objeto de estudios críticos y rigurosos por parte de investigadores como Catherine G. Bellver ${ }^{4}$, Emilio Mirós, Pilar Nieva de la Paz, Alfonso Sánchez Rodríguez y James Valender. Su temperamento inconformista y su personalidad la convirtieron en una mujer extraordinaria de su tiempo con múltiples facetas, pues, además de poeta y dramaturga, fue campeona de natación, guionista, editora, impresora y vendedora de libros.

Sin duda, fue una figura clave de las mujeres tan a menudo olvidadas de la Generación del 27, que investigadoras como Tània Balló han ayudado a sacar a la luz con su proyecto Las Sinsombrero: este nombre tiene sus orígenes en el acto transgresor de algunas de estas artistas que decidieron salir a la calle sin sombrero, pues "Según cuenta la pintora [Maruja Mallo], «Concha reñía mucho con sus padres». Un día decidió, en contra de las órdenes de su madre, salir a la calle sin sombrero: «Te tirarán piedras en la calle». «Me mandaré construir un monumento con ellas»" ${ }^{6}$. En las memorias de Méndez podemos observar la frecuencia de este tipo de respuestas ocurrentes a los reproches de sus padres: con el humor huía de una realidad densa; la comicidad era para Méndez aquello que Berger bautizó como un islote en medio del océano de la experiencia cotidiana ${ }^{7}$. Estas mujeres modernas, libres, con un enorme espíritu crítico y reivindicativo de la figura femenina como ser creativo por naturaleza propia, cuyas figuras son deudoras de los movimientos europeos feministas y sufragistas, tomaron conciencia de su capacidad intelectual y decidieron participar activamente en la vida pública. En España, la figura de esta nueva mujer se consolidó con la proclamación de la Segunda República en 1931. Shirley Mangini las califica de modernas y de Concha Méndez explica que "representa uno de los casos más interesantes de la moderna madrileña. Rechazó su vida lujosa, «de película»,

3. Paloma Ulacia Altolaguirre, Memorias habladas, memorias armadas, Renacimiento, Sevilla, 2018, p. 45.

4. Catherine Bellver, "Mothers, daughters and female tradition in the poetry of Concha Méndez", Revista Hispánica Moderna, 51.2 (1988), pp. 317-326.

5. Emilio Miró, "La contribución teatral de Concha Méndez", El teatro en España entre la tradición y vanguardia, eds. Dru Dougherty y María Francisc Vílches de Frutos, CSIC, Madrid, pp. 439-451.

6. Tània Balló, Las Sinsombrero, Espasa, Barcelona, 2016, p. 87. Entre ellas, además de la propia Concha Méndez, destacan artistas plásticas, dramaturgas y pensadoras como Rosa Chacel, Ernestina de Champourcín, Marga Gil Röesset, María Teresa León, Maruja Mallo, Ángeles Santos, María Zambrano, Josefina de la Torre y Carmen Conde.

7. Peter Ludwig Berger, La rialla que salva, La Campana, Barcelona, 1997, p. 364. 
para encontrarse, para reconciliarse con un «yo» que iba más allá de las diversiones de la década de los veinte, un yo poético que encontraba poesía en todo" ${ }^{8}$. Un "yo" que no solo se buscaba a sí misma, sino que también se implicaba en expandir su conocimiento y propulsar la emancipación de la mujer a través de organizaciones culturales: una de las más destacadas fue el Lyceum Club Femenino, con Concha Méndez y la escritora novecentista María de Maeztu como dos de las socias más relevantes.

El Lyceum Club, entre otras actividades de tipo intelectual, organizó el estreno y la representación de obras de teatro para adultos y de piezas de teatro infantil de autoras como Ernestina de Champourcín y la propia Concha Méndez. Es precisamente en el Lyceum Club donde, en 1929, Méndez estrenaría El ángel cartero, con motivo de la Fiesta de Reyes, y en donde, siete años después, en 1936, la autora realizó una lectura pública de una segunda pieza teatral para niños escrita en 1935: El carbón y la rosa. En el Lyceum Club también estrenó El personaje presentido (1935), drama para adultos escrito durante la estancia de la autora en Buenos Aires. Lyceum Club y Concha Méndez son, pues, un binomio que favoreció el progreso intelectual: por un lado, el centro contó en su programación teatral con la presencia de Méndez, una autora singular en el Madrid del momento, sobre todo por su labor de creación poética; por otro, Concha Méndez pudo mostrar, en un espacio cultural de la talla del Lyceum Club, a un grupo de intelectuales mayoritariamente feministas, su labor teatral, con la que estaba contribuyendo a la renovación del teatro infantil junto a autoras como Elena Fortún o Magda Donato.

De su labor como autora polifacética, una de las parcelas más destacadas, pero también a menudo más olvidada por la crítica, es la de escritora de teatro para niños, ya que sus obras forjaron un cambio en el panorama teatral infantil. El teatro escrito por Concha Méndez para niños debe entenderse dentro del contexto histórico del primer tercio del siglo XX, en el que un grupo de creadoras buscaron el éxito en la escena fuera de las estrechas convenciones del teatro tradicional y pedagógico de Pilar Contreras, Carolina Soto y Corro o Sor Felisa Girauta, quienes procuraban el adoctrinamiento moral y religioso en círculos católicos y en escenarios de colegios religiosos. Para Concha Méndez, el teatro infantil había de adecuarse al público y contener una gran dosis de humor. Según Nieva de la Paz, Concha Méndez fue "la autora que llevó a cabo el proyecto más ambicioso de renovación del género" ", partiendo del niño como receptor activo y crítico de las obras. En el teatro infantil, además de diversión, la trama debe permitir al niño posicionarse ante los hechos que se representan. Es lo que Méndez entiende por educación espiritual del nińo, que, a diferencia de la educación personal y de su instrucción

8. Shirley Mangini, Las modernas de Madrid, Península, Barcelona, 2001, p. 178.

9. Pilar Nieva de la Paz, "Revisando el canon: hacia una selección crítica del teatro escrito por mujeres en la España de entreguerras", Breve historia feminista de la literatura española (en lengua castellana), Anthropos, Barcelona, 1998, vol. V, p. 177. 
escolar (que son responsabilidad de la familia y de la escuela respectivamente), corre a cargo del $\operatorname{artista}^{10}$.

El teatro de Méndez es una amalgama perfecta entre tradición y modernidad. Observamos, por ejemplo, la presencia de los Reyes Magos en El ángel cartero; la trama de $E l$ pez engañado contiene claras reminiscencias al episodio bíblico en el que Jonás se encuentra dentro del vientre de una ballena después de ser engullido. Estas mismas situaciones y personajes se revisten de modernidad: así, por ejemplo, los Reyes Magos están acompañados por mecánicos, viajan en una avioneta y sus vestimentas combinan pasado y presente, al llevar puestos trajes de aviadores. Esta renovación de las temáticas respondía sin duda a una nueva manera de entender la literatura, a una manera propia de entender el vanguardismo que supo reflejar magistralmente en su obra con un sello personal irremplazable, como afirma Alfonso Sánchez Rodríguez a propósito de su obra poética: "es un vanguardismo, el suyo, más de reflejo personal, de temas, de motivos y de elementos construidos, que de lenguaje o forma"11.

Cabe destacar que según Concha Méndez el teatro y la poesía están intrínsecamente unidos: "Para hacer teatro, aunque sea teatro realista, hay que haber nacido poeta..."12. A la poesía debe añadirse la fantasía, el simbolismo y el humor como ejes vertebradores de su teatro, siendo este último elemento clave para mostrar la variedad de matices que Méndez quería ofrecer en sus obras, relativizando y suavizando las diferentes situaciones que se llevan a cabo en ellas. El ángel cartero (1929), El pez engañado (1933), Ha corrido una estrella (1934) y El carbón y la rosa (1935) son cuatro de sus piezas infantiles en las que se aprecia el uso del humor ${ }^{13}$. Observaremos, a continuación, como la autora utiliza el humor en los diálogos para hacerlos más ágiles y captar así la atención del espectador, sirviéndose además de juegos lingüísticos; el humor se hace presente con función socializadora que provoca el acercamiento con los distintos personajes y con el público. A esta función de acercamiento se le ha de añadir la de aliviar tensiones en los momentos de las tramas en los que surgen más conflictos; por último, veremos cómo se hace presente la ironía.

El pez engañado es una obra prolija en diálogos. Buena parte de la pieza teatral acontece en el interior de un pez donde conviven siete personajes que han sido engullidos por el animal. El humor actúa como una chispa que enciende la vivacidad de los diálogos desde el principio, dotándolos de agilidad, según podemos observar en la siguiente conversación que acontece en la primera escena de la obra, antes de que una de las nińas que interviene sea engullida por el pez:

10. Concha Méndez, El pez engañado; Ha corrido una estrella y Las barandillas del cielo, Asociación de Directores de Escena de España, Madrid, 2006, p. 39.

11. Alfonso Sánchez Rodríguez, "Concha Méndez y la vanguardia. Apuntes para un retrato de mujer moderna”, Concha Méndez en su mundo (1898-1986), ed. James Valender, Residencia de Estudiantes, Madrid, 2001, p. 119.

12. Concha Méndez, "Historia de un teatro", Concha Méndez en su mundo (1898-1986), p. 70.

13. El año indicado corresponde al de creación de las obras. 
NIÑA 1.- (Mirando siempre las regatas.) Ahora el dos va a adelantar al uno. ¡Los dos van al que más pueda!

NIÑA 2.- Ése va a ser el "Nautilus".

NIÑO 1.- ¿Por cuál apostaste tú?

NIÑA 2.- Por ése.

NIÑO 1.- ¿Y qué nos jugamos en definitiva?

NIÑA 2.- Lo que quieras.

NIÑO 1.- Si llega el mío gano yo y si llega el tuyo ganas tú.

NIÑO 4.- Naturalmente...

NIÑA 1.- Eso lo hubiera dicho cualquier tonto ${ }^{14}$.

En el diálogo anterior, a partir de un acercamiento de dos conceptos con significados parecidos "si llega el mío gano yo y si llega el tuyo ganas tú", el niño hace una deducción lógica. De manera parecida, el mismo niño que pronunciaba la frase anterior nos sorprende con una reflexión acerca de la relación arbitraria entre el significado y significante de las palabras que nos recuerda a la teoría sobre la naturaleza del signo lingüístico de Saussure ${ }^{15}$ :

NIÑO 1.- (Que ha estado haciendo esfuerzos por coger algo de entre una roca.) Menos mal que he podido atraparla...

NIÑO 4.- ¿El qué?

NIÑO 1.- Una margarita.

NIÑO 2.- Eso es una caracola.

NIÑO 1.- Que se llama margarita.

NIÑO 2.- ¿Por qué si en nada se parece a la flor?

NIÑO 1.- También tu prima se llama Margarita y tampoco se parece ${ }^{16}$.

La risa siempre ha sido un elemento donde encontrarse con los demás, por eso es generadora de complicidades. Las bromas y los chistes actúan como lugares de encuentro, al igual que los cuentos que se explicaban a la vera de la lumbre en las noches más frías; en las adversidades el humor actúa de salvavidas al que aferrarse y así lo vemos en El pez engañado, donde los protagonistas lo utilizan de parapeto para distanciarse de la situación complicada que están viviendo, pues como afirma Sala-Valldaura: "L'humor permet d'observar la realitat a partir d'una certa distància, admet que ens la prenguem amb alegria o, si més no, amb calma, i per això acostuma a relativitzar la gravetat. Una tal

14. Concha Méndez, El pez engañado. Ha corrido una estrella. Las barandillas del cielo, ed. Margherita Bernard, Asociación de Directores de Escena de España, Madrid, 2006, p. 68.

15. Ferdinand de Saussure, Curso de lingüistica general [Cours de linguistique générale], traducción, prólogo y notas de Amado Alonso, Losada, Buenos Aires, 2005, pp. 141-148.

16. Concha Méndez, El pez engañado..., p. 71. 
relativització contribueix a una vida menys agressiva i més civilitzada, tant personalment com col-lectivament" ${ }^{17}$.

Los niños protagonistas de El pez engañado relativizan la situación, hacen bromas y explican chistes. Esto les ayuda a convivir de una manera civilizada, apenas surgen conflictos y cuando deviene una preocupación, como en el diálogo siguiente por la salida del viejo al mar, en el humor buscan el consuelo y la calma:

NIÑA.- (Intranquila) ¡Ya se ha ido! ¿Volverá? ¿No le comerán los tiburones?

ÁRABE.- Es un pez viejo y ya sabéis que el pez grande se come al chico pero no al viejo.

(Todos rien menos el indio.)

INDIO.- ¡Qué chiste más malo!

NEGRITO.- Peores son los tuyos. El otro día me preguntó que si sabía en qué se diferencia un piano de cola de un sorbete.

INDIO.- Y como no supo contestar me [sic] le dije que cuando fuera a comprar un sorbete tuviera cuidado no fueran a darle un piano... ${ }^{18}$

Cabe añadir a esta función socializadora del humor que estos diálogos son interpretados por niños. De esta manera, siendo sus iguales los que les provocan la risa, se genera más acercamiento con el público infantil. Asimismo, como vemos en el diálogo anterior, se persigue una doble comunicación: la que se establece entre los personajes de la obra y la que espera crearse con el receptor. Y es que como afirma Pavis: "La risa es "comunicativa»; al que se ríe le es preciso al menos un partenaire para asociarse a él y reírse de lo que es mostrado. Al reírnos de un hombre cómico, determinamos además nuestra relación con él: aceptación o exclusión. La risa presupone la determinación de grupos socioculturales y de relaciones sutiles entre ellos. Es un fenómeno social"19. Cuando tratamos la temática del humor, es necesario mencionar el amplio y atávico debate de si deben o no existir límites. Sea como fuere, lo cierto es que hemos de conocer las diferencias que se establecen entre reírse de y reírse con. A propósito de ello, resulta pertinente explicitar la distinción que señalaba Sala-Valldaura: "Riurés de implica un alliberament del cos, un triomf sobre la por i, especialment, sobre les forces coercitives del món normalitzat i normativitzat, i el que s'anomena baixa comicitat ho representa molt bé. En canvi, riure amb

17. [El humor permite observar la realidad a partir de una cierta distancia, admite que nos la tomemos con alegría o, al menos, con calma, y por eso acostumbra a relativizar la gravedad. Una tal relativización contribuye a una vida menos agresiva y más civilizada, tanto personalmente como colectivamente]. Josep Maria Sala-Valldaura, Pensant el riure, Obrador Edèndum-Publicacions-Universitat Rovira i Virgili, Santa Coloma de Queralt, 2013, p. 12.

18. Concha Méndez, El pez engañado..., p. 85.

19. Patrice Pavis, Diccionario del teatro [Dictionarie du théâtre], trad. Jaume Melendres, Paidós, Barcelona, 2017, p. 81. 
s'acosta més a la definició de l'humor, en reconèixer l'altre com un igual, en respectar la dignitat de la persona" 20 .

En las obras de Concha Méndez encontramos las dos variantes preposicionales que acompañan al verbo reír, a veces como contraste para mostrar de manera pedagógica al público infantil esta diferencia. Cuando los personajes se ríen conjuntamente, nadie se molesta; en cambio, cuando se ríen de alguien aparece un desequilibrio relacional, y por ende, el conflicto:

NEGRITO.- Yo casi reviento de alegría. Me compraré merengues al desembarcar.

INDIO.- ¡Un negrito comiendo merengues! (Riendo) Ja. Ja. Ja.

(Rien todos.)

NEGRITO.- (Molesto) ¡No le veo la gracia!21

En esta sucinta aproximación sobre el binomio que conforman el humor y las obras teatrales infantiles de Concha Méndez, no se puede obviar el uso de la ironía puesto que resulta una pieza clave para entender su manera novedosa de enfocar el teatro. La encontramos en su dimensión humorística y en su papel transgresor de la moral. Su uso en el teatro infantil provoca la activación del pensamiento crítico en los niños. La ironía provoca el distanciamiento con la realidad que se presenta, provocando en los receptores la percatación de una situación insólita a partir de la ambigüedad que se plantea, por lo que pide colaboración en el receptor, al que necesita activo. Méndez consigue, así, dejar atrás la excesiva rigidez de las obras teatrales infantiles que la precedieron y evita aquello que Rosa Tabernero describe como un "menosprecio de la competencia del destinatario para generar sus propios significados" 22 .

En el siguiente fragmento de Ha corrido una estrella, que explica las aventuras y desventuras del romance entre un pastor y una estrella, el astro curiosea con el telescopio de los astrónomos lo que ocurre en la tierra. En las acotaciones se requiere explícitamente el tono irónico de los personajes:

ESTRELLA.- En aquel otro barco, que debe ser mercante, van unos fogoneros atizando la caldera. ¡Pobrecillos como sufren! ¡Parecen rendidos por el cansancio! ¡Pobrecillos! (Con ironía.) ¡Mire usted al capitán echándose un traguito en su camarote! ASTRÓNOMO 1.- (Irónico, a su discípulo.) ¿Has visto? Y éramos nosotros los curiosos, los mirones... ${ }^{23}$

20. [Reírse de implica una liberación del cuerpo, un triunfo sobre el miedo y, especialmente, sobre las fuerzas coercitivas del mundo normalizado y normativizado, y lo que se llama baja comicidad lo representa muy bien. En cambio, reirse con se acerca más a la definición del humor, se reconoce al otro como un igual, al respetar la dignidad de la persona]. Josep Maria Sala-Valldaura, Pensant el riure, p. 14.

21. Concha Méndez, El pez engañado..., p. 105.

22. Rosa Tabernero, Nuevas y viejas formas de contar, Prensas Universitarias de Zaragoza, Zaragoza, 2005, p. 26.

23. Concha Méndez, El pez engañado..., p. 122. 
En la misma escena, percibimos la ironía por el contexto y las situaciones, como en este caso la crítica a la hipocresía y a la superficialidad de la sociedad, ya sea en el ámbito doméstico o en el público:

ESTRELLA.- ¡Ah, miren, miren qué cosa tan graciosa ocurre tras los cristales de aquella ventana: una señora va a acostarse y se quita el peluquín! Y su marido deja en el vaso de agua sus dientes postizos. (Ríe a carcajadds.) Pero lo peor no es eso, sino que tiene una pierna de goma, que está poniendo sobre un sillón. (Vuelve a reír.) $[\ldots]$

ESTRELLA.- Lo que se ve ahora debe de ser un mitin político. ¡Qué bien gesticula el orador! Es entretenido ver cómo engaña al pueblo ${ }^{24}$.

En esta obra, el recurso irónico se emplea para la caracterización de algunos de sus personajes arquetípicos, sirviéndose de la antífrasis, que evidencia las contradicciones que presentan entre sus palabras y sus acciones:

BRUJA.- (Saliendo del cuarto rojo.) ¿Llegó el soplón?

PELIRROJO.- ¿Lo de soplón va por mí?

LADRÓN 2.- No le hagas caso, es una bruja loca.

PELIRROJO.- En cuanto me enteré eché a correr monte arriba para avisaros.

$[\ldots]$

PELIRROJO.- Espero que como siempre llevaré parte en la ganancia.

BRUJA.- No faltaba más. Para eso has sido el soplón.

PELIRROJO.- ¿Eso del soplón es con ánimo de ofenderme?

LADRÓN 3.- Si insistes en hacerle caso a la vieja peor para $\mathrm{ti}^{25}$.

La ironía en algunas ocasiones puede contener cierta crueldad y en determinados casos se acerca al sarcasmo. Así, es de manera sarcástica como la rosa se comporta con el carbón en la obra El carbón y la rosa. La risa que puede generar la situación al observar el acentuado contraste entre la dedicación del carbón a la rosa, y la indiferencia por parte de ella, se puede convertir en cierta compasión hacia el personaje:

CARBÓN.- Si el jardinero se confunde y vierte el agua en la estufa y no en la maceta...

ROSA.- Te hubieses apagado.

CARBÓN.- Te equivocas. Me hubiese mantenido ardiendo porque en un descenso en la temperatura te hubiese perjudicado y yo sé todo lo que vales y lo que para mí eres para consentir tal cosa. Si [sic]. Me hubiese mantenido ardiendo. La voluntad puede mucho. (La rosa ríe y coquetea, girando por la escena) ¿Te causa risa lo que dije?

24. Ibid., p. 122.

25. Ibid., p. 143. 
ROSA.- Me divierten tus pretensiones. Poco menos me has venido a decir que te debo la vida, o por lo menos mi salud. (Vuelve a reir [sic]).

CARBÓN.- Si [sic], ríe, ríe, ¿pero que [sic] harías sin mi calor en este invernadero?

ROSA.- ¿Y tu [sic], siendo carbón, que otra cosa puedes hacer que quemarte por mi [sic]?

CARBÓN.- En el mundo hay muchos niños que tienen frío.

ROSA.- ¡Pues vete con ellos! ${ }^{26}$

De las obras infantiles de Méndez es imprescindible destacar El ángel cartero por la transgresión a la tradición. La pieza trata la llegada de los Reyes Magos desde una perspectiva singular, pues toda ella se convierte en una ironía que subvierte la tradición de manera hiperbólica: desde el tratamiento de los personajes a las acciones que llevan a cabo. Los ecos de vanguardia no solo se reflejan en el argumento, sino que se muestran también en un nivel lingüístico en el que predomina el coloquialismo, "totalmente alejado de la altisonancia retórica al uso en el teatro infantil navideño" ${ }^{27}$. El propio título desafía al espectador, puesto que espera que sea el ángel el protagonista, al estilo del teatro escolar previo, pero la autora erige a la nińa como estrella. El personaje femenino, asimismo, no adquiere el rol de obediencia y prudencia habitual en las obras escolares de finales del XIX y principios del XX, sino que se muestra rebelde y contestataria, tratando al ángel y a los propios Reyes Magos como iguales, puesto que la autora los humaniza, ya desde el inicio de la obra: el ángel es un personaje terrenal que, si bien tiene reminiscencias de la tradición, como mensajero de Dios, se transforma en un humilde cartero que lleva una carta a una niña. Es asimismo una forma de extrañamiento hacer llegar a los Reyes Magos en avioneta, mostrando así la pasión de Méndez por los avances de la técnica y la modernidad. El atuendo de sus majestades presenta además el contraste entre tradición y contemporaneidad puesto que visten "uno de aviador, otro de alpinista y otro al modo ruso, con altas botas. Sobre estos trajes llevan largas capas de distintos y vivos colores, con turbantes cubriéndoles la cabeza" 28 .

El número 15 de Scriptura acogía un monográfico titulado Risas y sonrisas en el teatro de los siglos XVIII y XIX. Josep M. Sala-Valldaura, su coordinador, explicaba en su presentación: "La relativización con que miramos en los tiempos modernos ayuda a contemplar las incongruencias de nuestro mundo, y quizás si el homo faber soporta tanto se debe a su condición de homo ridens. Cuando falla la comicidad, todavía podemos convertir a nuestro prójimo o a uno mismo en homo ridiculus o recurrir a la inquisición irónica... que tan cerca está de proporcionarte la libertad"29. Como puede desprenderse

26. Concha Méndez, El carbón y la rosa, Caballo Griego, Madrid, 2008, pp. 12-13.

27. Pilar Nieva de la Paz, "El teatro infantil de Concha Méndez", en Concha Méndez en su mundo (18981986), p. 169.

28. Concha Méndez, El ángel cartero, Imprenta de Galo Sáez, Madrid, 1931, p. 137.

29. "Presentación de Risas y sonrisas en el teatro de los siglos XVIII y XIX", Scriptura, 15 (1999), p. 8. 
de todo lo expuesto, Concha Méndez se abastecía de humor para poder digerir el mundo en el que le había tocado vivir, la opresión y la discriminación las combatía con su creatividad artística y vital y su pasión viajera. Tal vez esa necesidad de crear nuevos mundos la llevó a escribir teatro para niños, que le permitía superar los límites de la realidad convencional. Su pluma transgresora parecía buscar una mirada nueva, una mirada que no coartara aprendizajes ni restringiera libertades a las niñas, para que la historia no se volviera a repetir. 